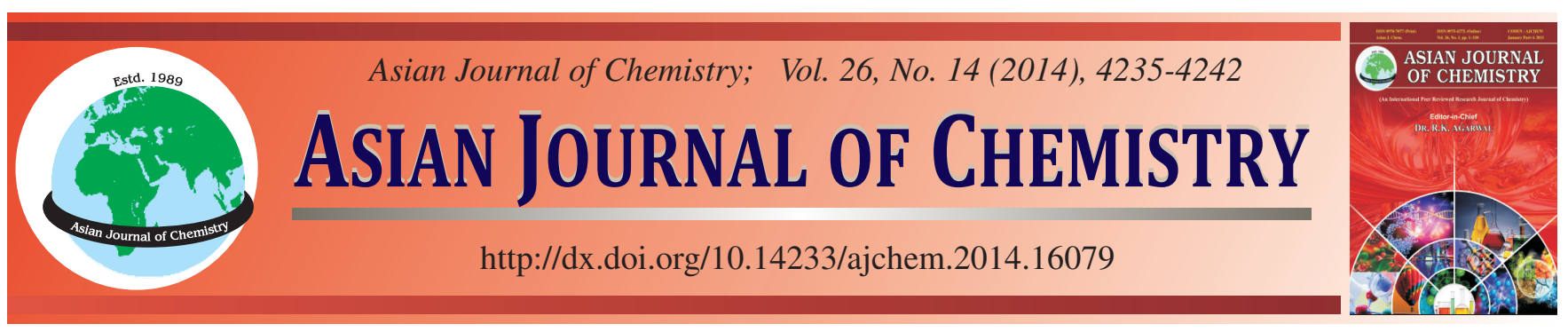

\title{
Preparation of Cationic Chitosan- $g$-Polyacrylamide and its Performance on Strengthening Paper and Antibacterial Activities
}

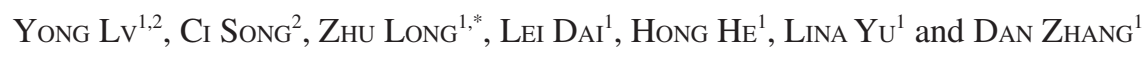

${ }^{1}$ Key Laboratory of Eco-textiles, Ministry of Education, Jiangnan University, Wuxi 214122, P.R. China

${ }^{2}$ School of Engineering and Information of Yiwu Industrial \& Commercial College, Yiwu 322000, P.R. China

*Corresponding author: Fax: +86 510 85912109; Tel: +86 510 85912107; E-mail: longzhu@ jiangnan.edu.cn

\begin{abstract}
A novel cationic polymer with long side chains (2,3-epoxypropyltrimethyl ammonium chloride (ETA) modified chitosan-graftpolyacrylamide, typically denoted as CTS-ETA- $g$-PAM) was prepared by grafting acrylamide onto the cationic modified chitosan. CTSETA- $g$-PAM samples were employed to modify the pulp fibers. The results indicated that: for the reaction of grafting polyacrylamide onto the cationic chitosan, the optimum initiator concentration, the degree of substitution (DS) of CTS-ETA (chitosan-2,3-epoxypropyltrimethyl ammonium chloride), reaction temperature and reaction time were $1.5 \mathrm{mmol} / \mathrm{L}, 0.369,35{ }^{\circ} \mathrm{C}, 5 \mathrm{~h}$, respectively. The CTS-ETA-g-PAM with higher percentage of grafting (PG) possessed more side chains, which could facilitate the formation of larger complexes among the CTS-ETA- $g$-PAM, microparticles and the fiber fines. The improved fiber wall strength would result in the improvement of the mechanical properties of the handsheets. As the percentage of grafting of CTS-ETA- $g$-PAM increased, no significant improvement was presented on antibacterial activities. However, the concentration of CTS-ETA- $g$-PAM had a strong influence on their antibacterial activities.
\end{abstract}

Keywords: Cationic chitosan, Grafting reaction, Mechanical properties, Antibacterial activities.

\section{INTRODUCTION}

The application of biodegradable polymers has been a successful method to enhance the strength properties of cellulosic fiber networks ${ }^{1-3}$. These include carboxymethyl cellulose ${ }^{4}$, cellulose acetate ${ }^{5}$, cationic $\operatorname{starch}^{6}$ and PVA ${ }^{7}$. Each of these polymers can be non-toxic, environmentally friendly and compatible with cellulosic surfaces so that it would not disrupt the hydrogen bonding among celluloses. In addition, interacting more strongly with the cellulose substrates could make the retention more efficient ${ }^{8}$. Chitosan, one of the most abundant materials that can be easily obtained in nature, has been applied in a variety of areas due to its unique properties, such as film forming ability, biodegradability, antibacterial activity and biocompatibility ${ }^{9-14}$.

Ordinarily, chitosan was introduced into paper industry as a dry strength additive and an antimicrobial agent ${ }^{8,15-17}$. However, its poor water solubility, particularly under neutral or alkaline environments, limited its application in papermaking ${ }^{18,19}$. With the development of paper-making system, transferring gradually from acidic to neutral and alkaline, regular chitosan becomes inconvenient in the modern paper making process ${ }^{20}$. There would be neither flocculation nor dewatering of reed pulp with chitosan, because regular chitosan cannot be dissolved in a neutral or alkaline condition.
To address this difficulty, chitosan has been chemically modified $^{15,21,22}$ and the modified chitosan has been employed as a retention aid in papermaking. Among various methods, one effective way is to modify chitosan with quaternary ammonium salt ${ }^{17,23,24}$. Cellulosic pulp gains a negative net charge after being bleached by chemicals, while chitosan after being quaternized turns into cationic derivatives. Thus quaternary ammonium salt of chitosan interacts strongly with cellulosic substrates via the electrostatic attraction. However, chitosan modified by quaternary ammonium salt does not show a good ability of bridging flocculation owing to its small molecular weight. Another way is graft polymerization ${ }^{25-27}$. This reaction is capable of introducing some synthetic functional polymers as side chains to the backbone of chitosan. It is well known that polyacrylamide (PAM) is a type of water-soluble polymer with high flocculating efficiency ${ }^{28,29}$. Furthermore, the long polyacrylamide side chains were beneficial to bridging flocculation and improved the flocculating performance ${ }^{30}$. Therefore, the cationic chitosan with cationic groups and long polyacrylamide side chains has dual functions on improving the bridging flocculation and paper strength. Derivations of the cationic starch and guar gum to improve the mechanical properties of paper were previously reported ${ }^{31-33}$. However, to our knowledge, it is the first time to develop a new cationic chitosan bearing polyacrylamide side chains with better mechanical properties. 
In this work, a novel cationic polymer with long side chains (CTS-ETA-g-PAM) was successfully prepared by grafting acrylamide onto main chains of cationic modified chitosan. The effects of initiator concentration, degree of substitution (DS) of CTS-ETA, reaction temperature and reaction time on the percentage of grafting (PG) of CTS-ETA-g-PAM were investigated. The final product was characterized by FTIR and ${ }^{1} \mathrm{H}$ NMR. The mechanical and antibacterial activities of the handsheets fabricated from the modified pulp fibers were evaluated and discussed in details.

\section{EXPERIMENTAL}

Chitosan (m.w. $235 \mathrm{KDa}$ ) was purchased from Qingdao Shengyang Chemistry Industry Co. (Shandong, China). The degree of deacetylation is $91 \%$ determined by potential titration method $^{34}$. 2,3-epoxypropyltrimethyl ammonium chloride ETA with weight ratio of $96 \%$ was supplied by Yantai Sangong Fine Chemical Industry Limited Company. Cellulose substrates, peroxide bleached reed kraft pulp, were provided by Chenming Papermaking Co. (Wuhan, China). The pulp refining was carried out according to TAPPI T 248 with a PFI refiner. S. aureus and gram-negative bacteria Escherichia coli were provided by School of Food Science and Technology in Jiangnan University. Acrylamide (AM) and all the other reagents were of analytical grade and used without further purification.

Preparation of CTS-ETA-g-PAM: CTS-ETA-g-PAM was prepared by grafting acrylamide onto main chains of the cationic modified chitosan, as shown in Fig.1. Firstly, chitosan was added to isopropyl alcohol in a three-necked flask and then agitated at $60{ }^{\circ} \mathrm{C}$ for $0.5 \mathrm{~h}$. Subsequently, ETA aqueous solution was added into the flask. After $8 \mathrm{~h}$, the mixture was cooled and filtrated with methyl alcohol. The precipitate, the primary product, was dried and distilled with acetone in a soxhlet for $12 \mathrm{~h}$ to eliminate the homopolymer. The final product was obtained after drying at $80{ }^{\circ} \mathrm{C}$.

In a typical experiment, the grafting reaction was carried out in a $250 \mathrm{~mL}$ four-neck flask by first dissolving a certain amount of CTS-ETA in $2 \%$ acetic acid solution followed by the addition of the $0.6 \mathrm{~mol} / \mathrm{L}$ aqueous acrylamide solution. The reactor was then purged with nitrogen flow and the mixture was heated to $30{ }^{\circ} \mathrm{C}$. After $0.5 \mathrm{~h}$ of stirring under $\mathrm{N}_{2}$ atmosphere, a certain amount of the $\mathrm{Ce}(\mathrm{IV})$ containing initiator was added in the form of aqueous solution of ceric ammonium nitrate. After $5 \mathrm{~h}$, the reaction product was precipitated in acetone. The precipitate was filtered off and rinsed with distilled water then dried in vacuum to constant weight at room temperature The dried product was extracted with acetone/water (volume ratio $=40: 60$ ) mixture for $24 \mathrm{~h}$ to remove the homopolymer of acrylamide.

Characterization of CTS-ETA-g-PAM: The FT-IR spectra of CTS-ETA- $g$-PAM were recorded on a Perkin-Elmer FT-IR spectrometer (Spectrum GX). The ${ }^{1} \mathrm{HNMR}$ spectra were recorded on an Avance 400 (Bruker, Germany) spectrometer operating at $400 \mathrm{MHz}$. The degree of substitution (DS) of CTS-ETA was measured by titrating the amount of chloride ions on the CTSETA with aqueous solution of $\mathrm{AgNO}_{3}{ }^{35}$. The percentage of grafting was calculated as follows:

$$
\mathrm{PG}=\left(\mathrm{W}_{1}-\mathrm{W}_{2}\right) / \mathrm{W}_{2} \times 100 \%
$$

where $\mathrm{PG}$ is the percentage of grafting $(\%), \mathrm{W}_{1}$ is the weight of product $(\mathrm{g})$ and $\mathrm{W}_{2}$ is the weight of CTS-ETA $(\mathrm{g})$.

Paper-sheet preparation and properties: The pulp was soaked in water for $24 \mathrm{~h}$ and mixed $(0.5 \%$ consistency) by a laboratory mixer after disintegration in a standard disintegrator at $20000 \mathrm{rpm}$ for a total of 15,000 revolutions. It was then

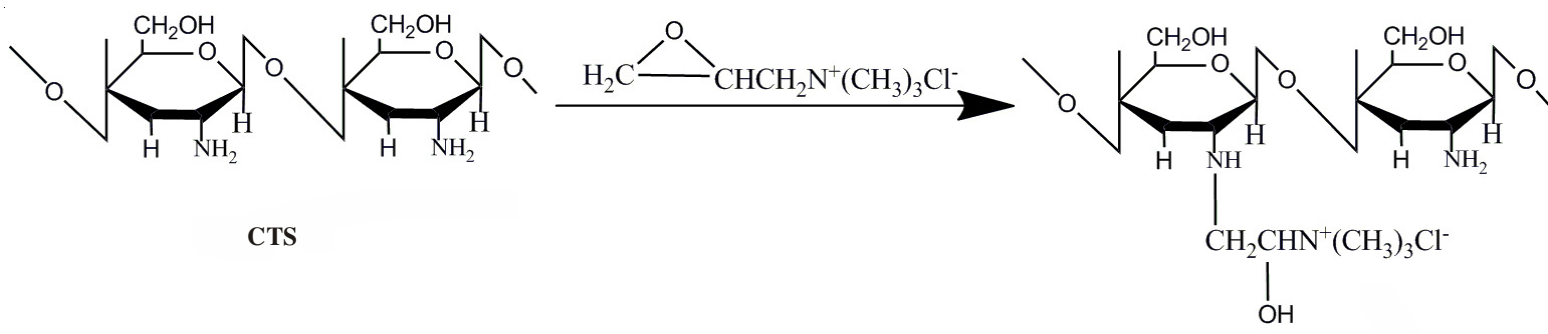

CTS-ETA-g-PAM

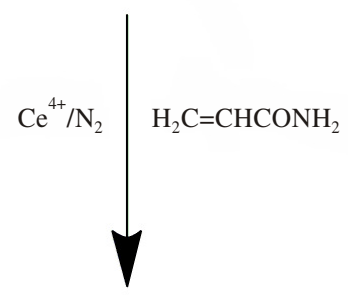<smiles>[M]C(C)C(C)C(C)(C)C</smiles>

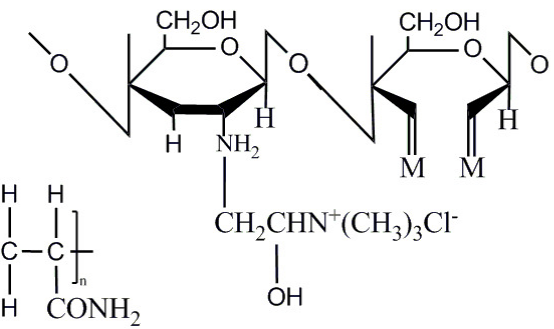

Fig. 1. Synthesis route of CTS-ETA-g-PAM 
rinsed three times with deionized water and then filtered. 2.0 $\mathrm{g}$ of pulp fibers dispersed in distilled water (3 wt. \%) were added into a 3-neck flask and kept at $\mathrm{pH} 7.0$ and $30^{\circ} \mathrm{C}$ for $1 \mathrm{~h}$. Various dosages of CTS-ETA- $g$-PAM were added into the fiber suspensions, which were stirred for $2 \mathrm{~h}$ at $90 \mathrm{rpm}$ before use. Paper sheets were made from the fibers modified with CTSETA- $g$-PAM according to TAPPI T 205 and then dried at an elevated temperature of $110^{\circ} \mathrm{C}$ for $0.5 \mathrm{~h}$ using an electric dryer.

The tensile and tear strengths were measured according to TAPPI T 494 and TAPPI T 403, respectively. Dynamic light scattering (DLS, Malvern, UK) was employed to determine the zeta potential values of the fine particles in suspensions. All suspensions with different dosages of CTS-ETA- $g$-PAM were gently agitated for $20 \mathrm{~min}$ and then centrifuged for $2 \mathrm{~min}$ at $2000 \mathrm{rpm}$ before measurements. To investigate the relation between the PG of CTS-ETA-g-PAM and adsorption on the retention in the pulp suspension, $0.4 \mathrm{~g}$ of calcium carbonate was added into the pulp. The ash content of the paper sheets can illustrate the retention of CTS-ETA-g-PAM.

Evaluation of antimicrobial activity: The antibacterial activity of the handsheets with various PG of CTS-ETA-gPAM against E. coli and Staphylococcus aureus were evaluated based on the inhibition rate which were determined on the basis of Chinese Industrial Standard (GB15979-2002).

The inhibition rate $(\mathrm{X})$ was defined as:

$$
\mathrm{X}=\left(\mathrm{N}_{1}-\mathrm{N}_{2}\right) / \mathrm{N}_{1} \times 100 \%
$$

where $\mathrm{N}_{1}$ and $\mathrm{N}_{2}$ are the numbers of colony on the plates before and after inhibition, respectively.

\section{RESULTS AND DISCUSSION}

Orthogonal test on synthesis of CTS-ETA: The cationic modification of chitosan using ETA is a routine method for improving the dissolubility and charge density of chitosan ${ }^{16,36}$. To obtain a series of CTS-ETA with various DS, an orthogonal test was performed. Based on the experimental design, the orthogonal array $\mathrm{L}_{16}(44)$ was selected to organize the parameters. In the orthogonal test, four controllable variables (reaction temperature, molar ratios of ETA/CTS, concentration of ETA solution and reaction time) were selected, each at four levels. The variables and their test levels are listed in Table-1.

TABLE-1

INVESTIGATED VARIABLES AND THEIR LEVELS

\begin{tabular}{lcccc}
\hline \multirow{2}{*}{\multicolumn{1}{c}{ Variables }} & \multicolumn{4}{c}{ Levels } \\
\cline { 2 - 5 } & 1 & 2 & 3 & 4 \\
\hline A: reaction temperature $\left({ }^{\circ} \mathrm{C}\right)$ & 60 & 70 & 80 & 90 \\
B: molar ratios of ETA/CTS & 1 & 3 & 5 & 7 \\
C: Concentration of ETA solution $(\%)$ & 20 & 30 & 40 & 50 \\
D: reaction time (h) & 4 & 6 & 8 & 10 \\
\hline
\end{tabular}

The results are listed in Table-2. It is obvious that the order of influence among all variables is $\mathrm{B}>\mathrm{A}>\mathrm{C}>\mathrm{D}$. The variance of molar ratio of ETA/CTS is the largest and level 2 is optimal according to the orthogonal test above. The optimum level for each variable is A3B2C2D3. Thus the optimum reaction conditions were obtained as follows: the optimum reaction temperature, the molar ratio of ETA/CTS, the concentration of ETA and the reaction time are $80{ }^{\circ} \mathrm{C}, 3,30 \%$ and $8 \mathrm{~h}$, respectively.

\begin{tabular}{|c|c|c|c|c|c|}
\hline \multicolumn{6}{|c|}{$\begin{array}{c}\text { TABLE-2 } \\
\text { EXPERIMENTAL ARRANGEMENT AND TEST RESULTS }\end{array}$} \\
\hline No. & $\mathrm{A}$ & $\mathrm{B}$ & $\mathrm{C}(\%)$ & $\mathrm{D}$ & DS \\
\hline 1 & 60 & 1 & 20 & 4 & 0.369 \\
\hline 2 & 60 & 3 & 30 & 6 & 0.736 \\
\hline 3 & 60 & 5 & 40 & 8 & 0.767 \\
\hline 4 & 60 & 7 & 50 & 10 & 0.625 \\
\hline 5 & 70 & 1 & 30 & 8 & 0.653 \\
\hline 6 & 70 & 3 & 20 & 10 & 0.776 \\
\hline 7 & 70 & 5 & 50 & 4 & 0.828 \\
\hline 8 & 70 & 7 & 40 & 6 & 0.759 \\
\hline 9 & 80 & 1 & 40 & 10 & 0.676 \\
\hline 10 & 80 & 3 & 50 & 8 & 1.015 \\
\hline 11 & 80 & 5 & 20 & 6 & 0.851 \\
\hline 12 & 80 & 7 & 30 & 4 & 0.958 \\
\hline 13 & 90 & 1 & 50 & 6 & 0.698 \\
\hline 14 & 90 & 3 & 40 & 4 & 0.980 \\
\hline 15 & 90 & 5 & 30 & 10 & 0.944 \\
\hline 16 & 90 & 7 & 20 & 8 & 0.858 \\
\hline K1 & 0.624 & 0.599 & 0.714 & 0.784 & 0.624 \\
\hline K2 & 0.754 & 0.877 & 0.823 & 0.761 & 0.754 \\
\hline K3 & 0.875 & 0.847 & 0.795 & 0.823 & 0.875 \\
\hline K4 & 0.870 & 0.800 & 0.791 & 0.755 & 0.870 \\
\hline Variance & 0.251 & 0.278 & 0.109 & 0.068 & 0.251 \\
\hline
\end{tabular}

\section{Effect of polymerization variables on grafting percentage} of CTS-ETA-g-PAM

Initiator concentration: When other factors are constant, the effect of $\mathrm{Ce}(\mathrm{IV})$ concentration on grafting parameters is shown in Fig. 2 (A). The values of PG became rising initially with increasing $\mathrm{Ce}(\mathrm{IV})$ concentration, however, the curve started to go down when the Ce(IV) concentration was over the optimum amount of $1.5 \mathrm{mmol} / \mathrm{L}$.

This result may be explained by the fact that a further increase in $\mathrm{Ce}(\mathrm{IV})$ concentration accelerated the reaction of $\mathrm{Ce}(\mathrm{IV})$ and radicals, which may terminate the chain propagation reaction, thus decreasing grafting parameters. This observation indicated that the optimal $\mathrm{Ce}(\mathrm{IV})$ concentration was $1.5 \mathrm{mmol} / \mathrm{L}$.

Degree of substitution of CTS-ETA: The degree of substitution (DS) of CTS-ETA has significant impact on the physical properties and reactive activity of CTS-ETA. Furthermore, it is able to affect the percentage of grafting and properties of the products. The percentage of grafting as a function of DS of CTS-ETA is shown in Fig. 2 (B). With increasing DS of CTS-ETA, the values of PG decreased. When the DS of CTS-ETA is above 0.369 , the values of PG decrease significantly. We suggest that the quaternary ammonia groups on CTS-ETA increased the steric hindrance, which arrested the grafting reaction. In consideration of the dissolubility of CTSETA and the percentage of grating, the optimal DS of CTSETA was 0.369 .

Reaction temperature: The grafting reactions were carried out at various temperatures between 25 and $45{ }^{\circ} \mathrm{C}$, while keeping the other variables constant. As shown in Fig. 2 (C), PG increased initially and then decreased with further increasing temperature. This is attributed to the fact that higher temperature favored the activation of macroradicals. Thus it facilitate accelerating the diffusion and mobility of the monomers from the aqueous phase to the backbone. However, a further increase in temperature decreases PG parameters 

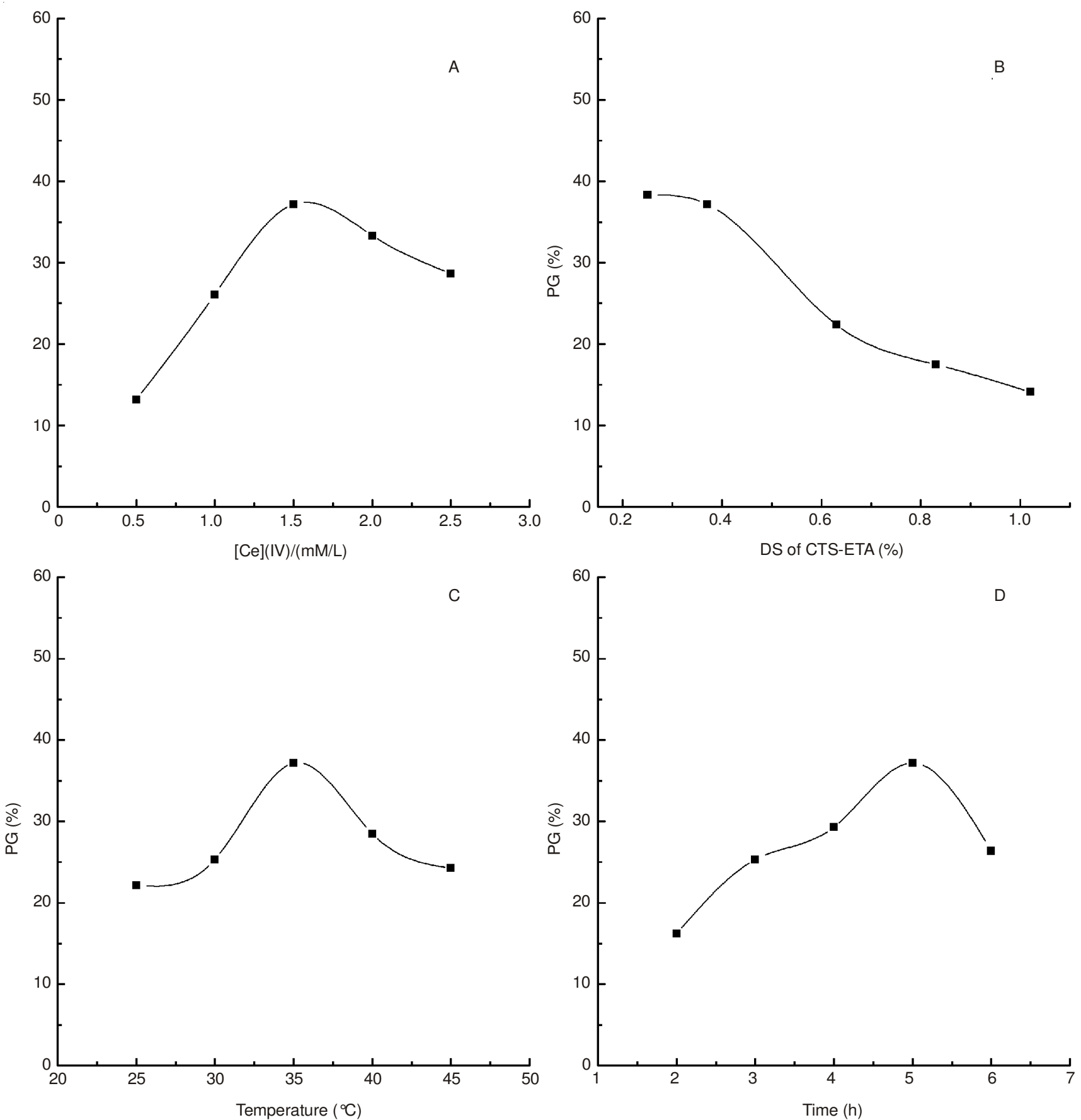

Fig. 2. Grafting percentage of CTS-ETA-g-PAM as functions of various parameters. Parameter A: initiator concentration (DS of CTS-ETA $=0.369$, CTS$\mathrm{ETA}=2 \mathrm{~g}$, acrylamide $=8 \mathrm{~g}, \mathrm{~T}=35^{\circ} \mathrm{C}$, reaction time $=5 \mathrm{~h}$ ); Parameter B: DS of CTS-ETA ([Ce(IV) $]=1.5 \mathrm{mmol} / \mathrm{L}, \mathrm{CTS}$-ETA $=2 \mathrm{~g}$, acrylamide $=8$ $\mathrm{g}, \mathrm{T}=35^{\circ} \mathrm{C}$, reaction time $\left.=5 \mathrm{~h}\right)$; Parameter $\mathrm{C}$ : reaction temperature $([\mathrm{Ce}(\mathrm{IV})]=1.5 \mathrm{mmol} / \mathrm{L}$, DS of CTS-ETA $=0.369$, CTS-ETA $=2 \mathrm{~g}$, acrylamide $=8 \mathrm{~g}$, reaction time $=5 \mathrm{~h}) ;$ Parameter D: reaction time $\left([\mathrm{Ce}(\mathrm{IV})]=1.5 \mathrm{mmol} / \mathrm{L}, \mathrm{DS}\right.$ of CTS-ETA $=0.369, \mathrm{CTS}-\mathrm{ETA}=2 \mathrm{~g}$, acrylamide $\left.=8 \mathrm{~g}, \mathrm{~T}=35^{\circ} \mathrm{C}\right)$

because of accelerating of termination reaction and increasing chance of chain transfer reaction, which leads to the increase in the amount of homopolymer. This observation demonstrates that the optimal reaction temperature is $35^{\circ} \mathrm{C}$.

Reaction time: The grafting reactions were carried out at different reaction time ranging from 2 to $6 \mathrm{~h}$ and keeping the other variables constant. As shown in Fig. 2 (D), it is found that PG increased rapidly within $5 \mathrm{~h}$ but decrease slowly with longer reaction time. The results coincided with Law of free radical reactions ${ }^{37}$. The grafting reaction mainly occurs at the initiation stage. When the reaction time reaches a certain extent, the number of grafting becomes saturated. A longer period of reaction time could benefit the amount of homopolymer merely. This observation indicated that the optimal reaction temperature is $5 \mathrm{~h}$.

Characterization of CTS-ETA-g-PAM: The IR spectra of chitosan (CTS), CTS-ETA and CTS-ETA- $g$-PAM were shown in Fig. 3. The absorption band at $1655 \mathrm{~cm}^{-1}$ in CTS is referenced as amide I bands and the absorption band at 1592 $\mathrm{cm}^{-1}$ is ascribed to the $\mathrm{N}-\mathrm{H}$ bending mode in the primary amine ${ }^{38}$. The absorption band of $-\mathrm{NH}_{2}$ in CTS-ETA decreased, suggesting that $\mathrm{N}$-alkylation in CTS occurred. Compared with CTS, CTS-ETA produced a band at $1470 \mathrm{~cm}^{-1}$, which could be attributed to the methyl groups of ammonium ${ }^{39}$. Further- 


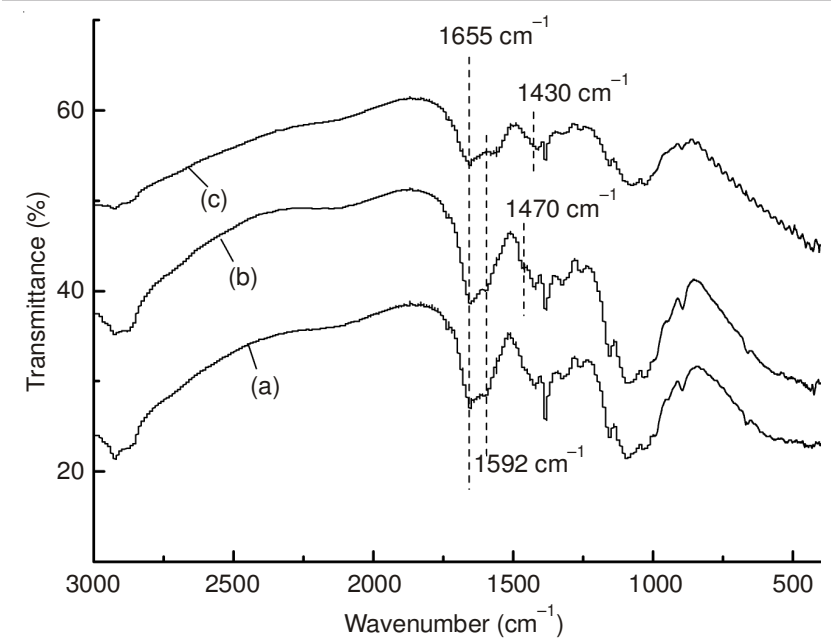

Fig. 3. FTIR spectra of chitosan (a), CTS-ETA (b) and CTS-ETA-g-PAM (c)

more, comparison of the FTIR spectra of CTS-ETA- $g$-PAM and CTS-ETA shows that a peak appeared at $1430 \mathrm{~cm}^{-1}$, which was due to the C-N stretching in the polyacrylamide, which further supported that a graft reaction occurred.

On the other hand, ${ }^{1} \mathrm{H}$ NMR was applied to investigate the structures of the copolymers. Fig. 4 shows ${ }^{1} \mathrm{H}$ NMR spectra of chitosan, CTS-ETA and CTS-ETA-g-PAM. Fig. 4 (a) shows the signal of the $\mathrm{H} 2$ proton (about $2.89 \mathrm{ppm}$ ), the H3-H6 protons (about 3.25-3.70 ppm) and the $\mathrm{H} 1$ proton (about 4.56 ppm) of chitosan ${ }^{40}$. As to the ${ }^{1} \mathrm{H}$ NMR spectrum of CTS-ETA (Fig. 4 (b)), a new peak at around 4.01 ppm was found and corresponded to the resonance of methylene proton $(\mathrm{H} 7)$ of ETA. Furthermore, an intense peak appeared at $2.89 \mathrm{ppm}$, which was attributed to the methyl protons (H8) in quaternary ammo- nium groups. The peaks at 1.32 and $1.91 \mathrm{ppm}$ are observed in Fig. 4 (c). They were corresponded to the characteristic signals of polyacrylamide (H9 and H10), respectively. This result strongly supported the existence of the grafting reaction. Therefore, both of the FTIR and ${ }^{1} \mathrm{H}$ NMR spectra confirmed that CTS-ETA-g-PAM was successfully obtained.

Influence of PG and concentration of CTS-ETA-gPAM on paper mechanical properties: The products CTSETA- $g$-PAM with various PG $(0,15.2,20.3,25.6$ and $31.3 \%)$ were tested at the same concentration of $0.2 \%$. The influences of PG of CTS-ETA- $g$-PAM on the strength effect of handsheet were plotted in Fig. 5. It is obvious that the physical properties increased with higher PG of CTS-ETA- $g$-PAM. The modified products with higher $\mathrm{PG}$ prossess more side chains and more side chains could facilitate the formation of larger complexes among CTS-ETA-g-PAM, microparticles and fiber fines, as shown in Fig. 6.

It is generally accepted that the greater improvement in the strength of paper-sheets can be made with larger polymers ${ }^{41,42}$. Additionally, the larger complexes can bridge the fibers more efficiently. Therefore, they can develop more contact areas between fibers, thus improving the fiber bonding dramatically.

The ash content of the paper-sheet can demonstrate the retention of CTS-ETA- $g$-PAM. The curves shown in Fig. 7 revealed that the ash content raised with higher PG of CTSETA-g-PAM. This result provided solid evidence that more PG of CTS-ETA-g-PAM had superior retention performance.

Fig. 8 shows the tensile strength and burst indices of the networks made from the fibers modified with various concentrations of CTS-ETA- $g$-PAM. CTS-ETA- $g$-PAM marginally
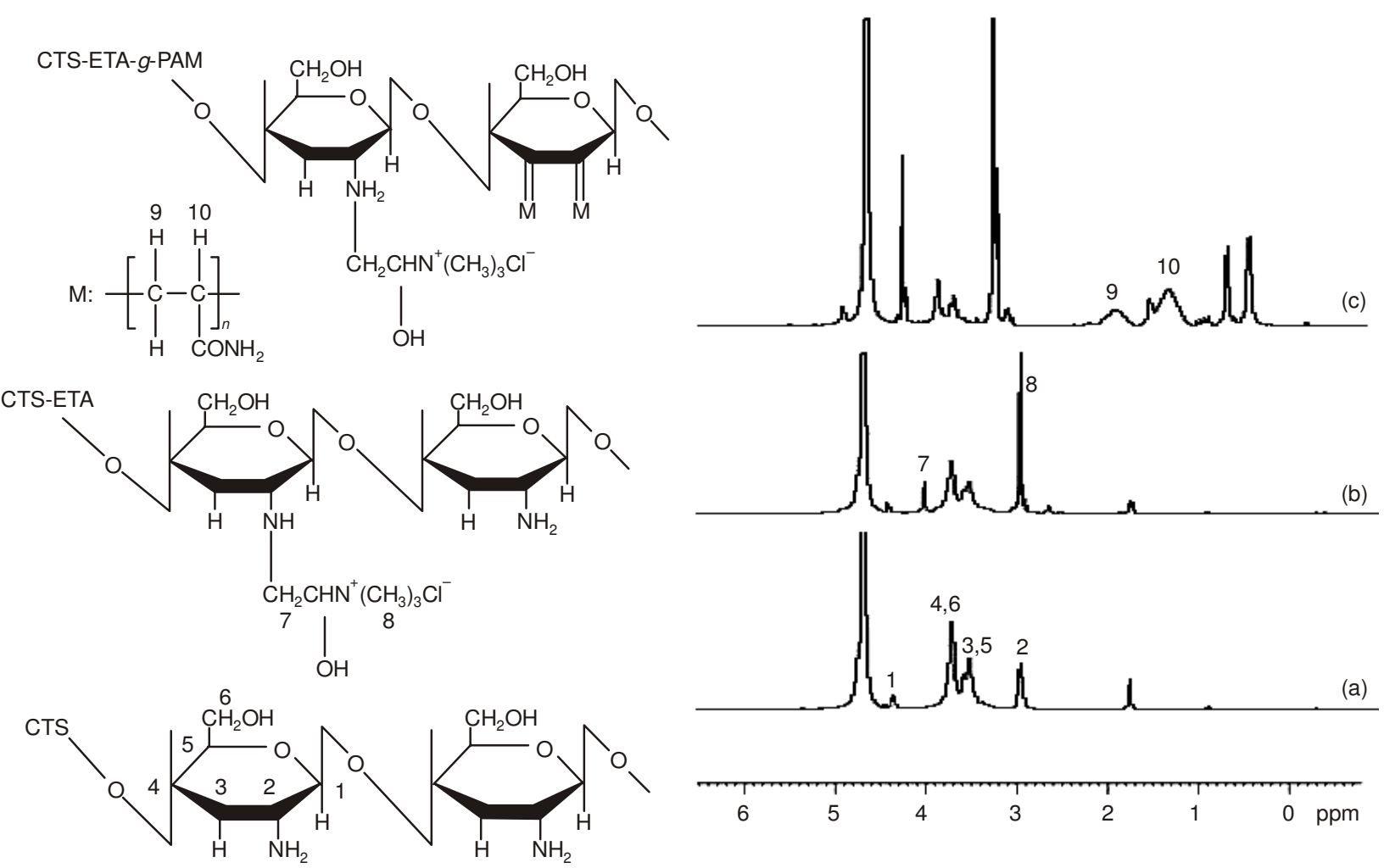

Fig. $4 .{ }^{1} \mathrm{H}$ NMR spectra of chitosan (a), CTS-ETA (b) and CTS-ETA-g-PAM (c) 

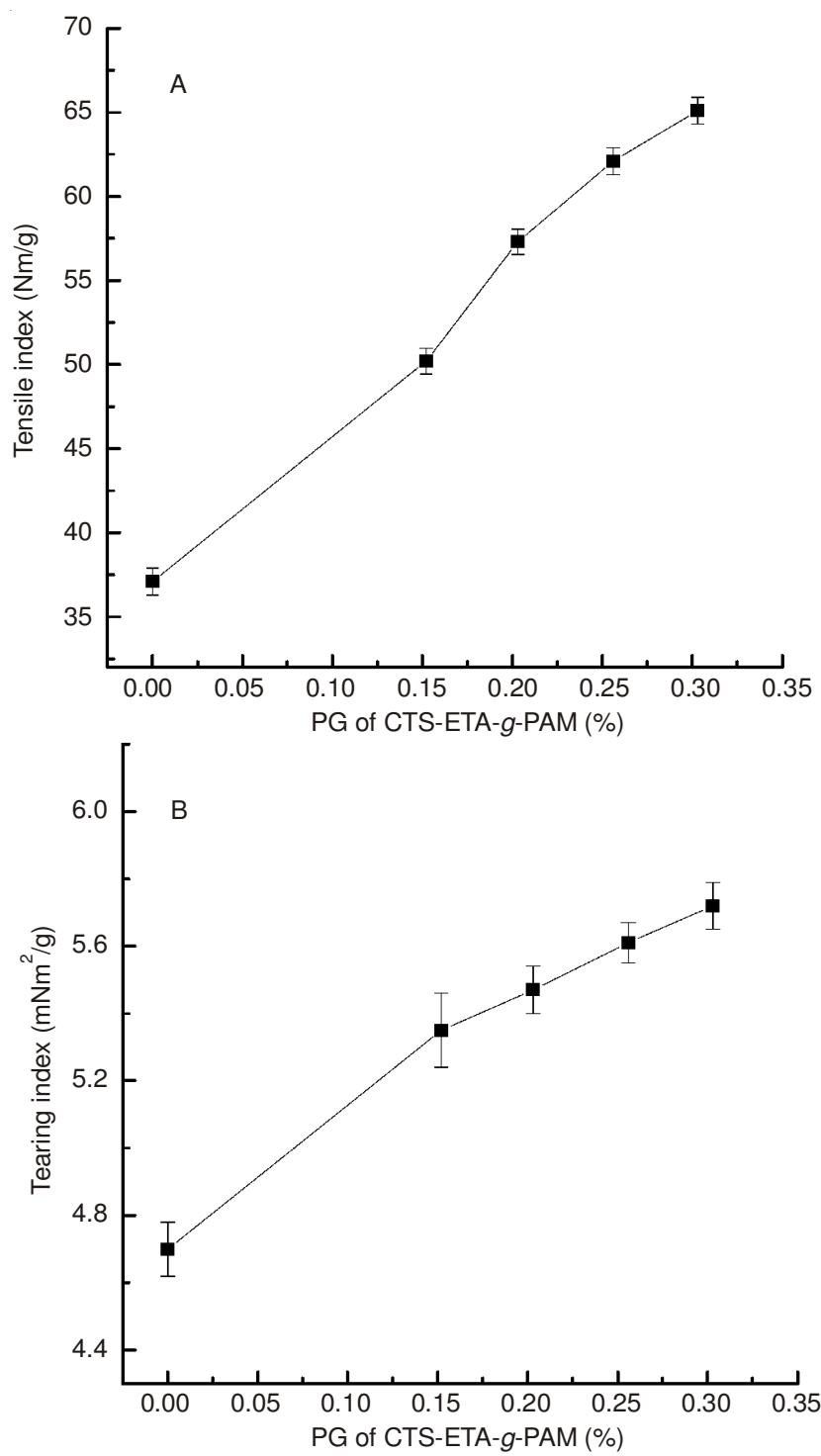

Fig. 5. Mechanical properties of the handsheets with different PG of CTSETA- $g$-PAM

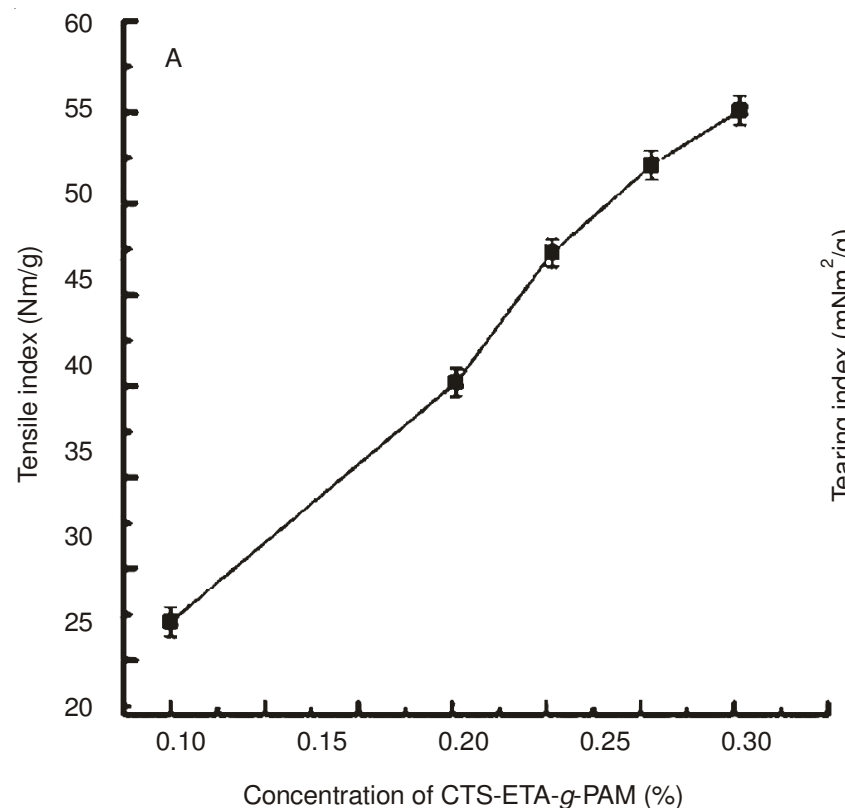

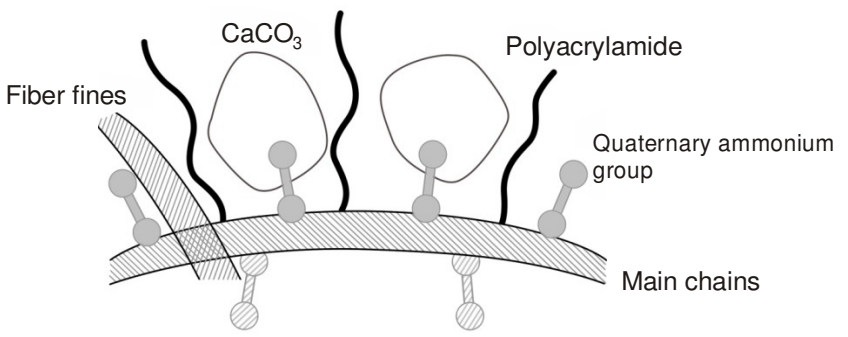

Fig. 6. Illustration of the interaction among CTS-ETA-g-PAM, microparticles and fiber fines

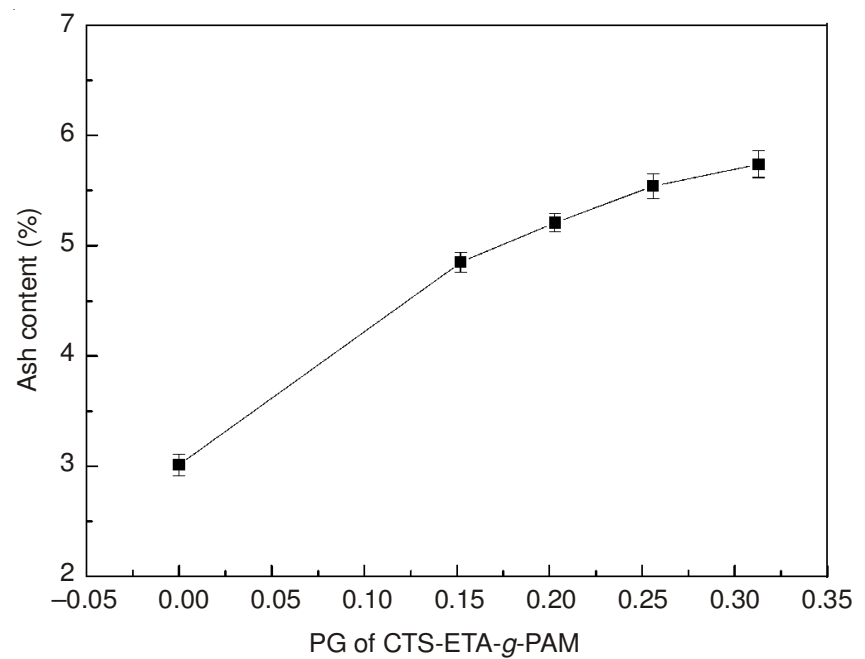

Fig.7. Ash content of the paper-sheet upon addition of CTS-ETA-g-PAM (the concentration of CTS-ETA- $g$-PAM:0.2\%)

improved the strength of the fiber network in the CTS-ETA$g$-PAM polymer system, owing to the limited adsorption of CTS-ETA on fibers. However, the CTS-ETA- $g$-PAM was more effective than CTS-ETA in improving the strength and its effectiveness was more pronounced at a higher polymer dosage.

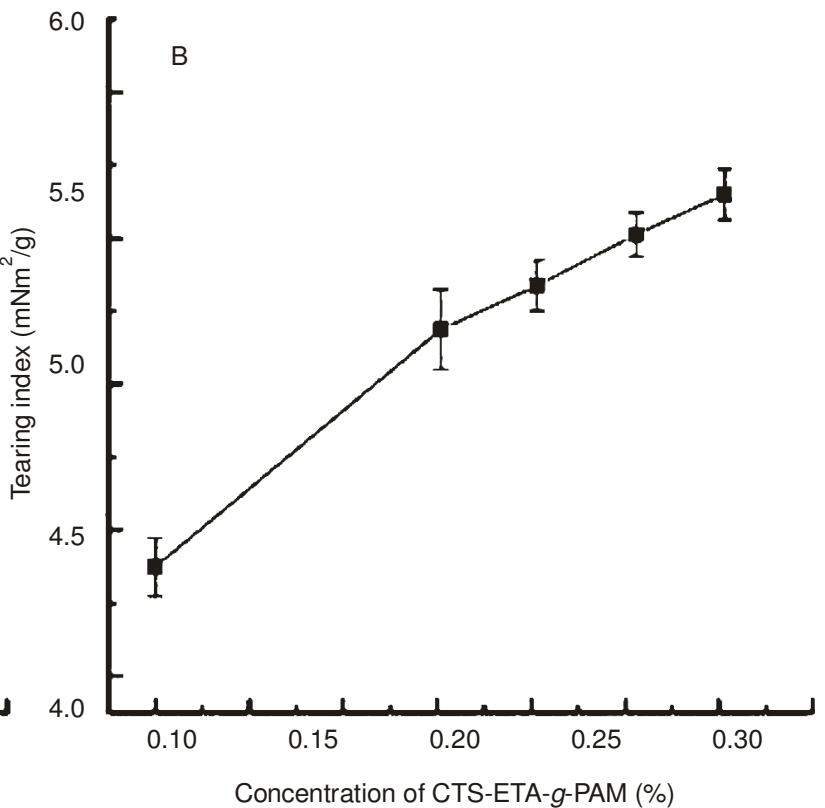

Fig. 8. Mechanical properties of the handsheets upon adding different concentration of CTS-ETA-g-PAM ((-m-: CTS-ETA, -•-: CTS-ETA-g-PAM)) 
The molecular structure of CTS-ETA has a linear backbone with quaternary amino group, thus the polymer possesses high charge density. While grafting the acrylic amide side chains, acrylic amide group has a zwitter ionic feature, which can decrease the charge density of the CTS-ETA. The lowcharged polymers might develop the tail-and-loop configuration, whereas the high-charged ones might develop the flattened configuration on fibers ${ }^{43}$. Therefore, the low-charged polymers may extend and occupy less surface area than the high-charged ones on the fibers, thus adsorbing more lowcharged polymers on the surface. Additionally, the repulsion force occured between the adsorbed polymers on the fiber surface and the polymer approaching to the fibers from the bulk $^{42}$. Apparently, higher charge density of polymers leads to stronger repulsion force, which impairs the adsorption of polymers onto the fiber surfaces ${ }^{44,45}$.

Fig. 9 shows the zeta potential of fiber fines adsorbed with CTS-ETA- $g$-PAM. As expected, a larger amount of CTSETA- $g$-PAM is needed to make the zeta potential of the suspension close to zero than CTS-ETA, which indicated that CTS-ETA- $g$-PAM facilitated their retention and improvement of the mechanical properties.

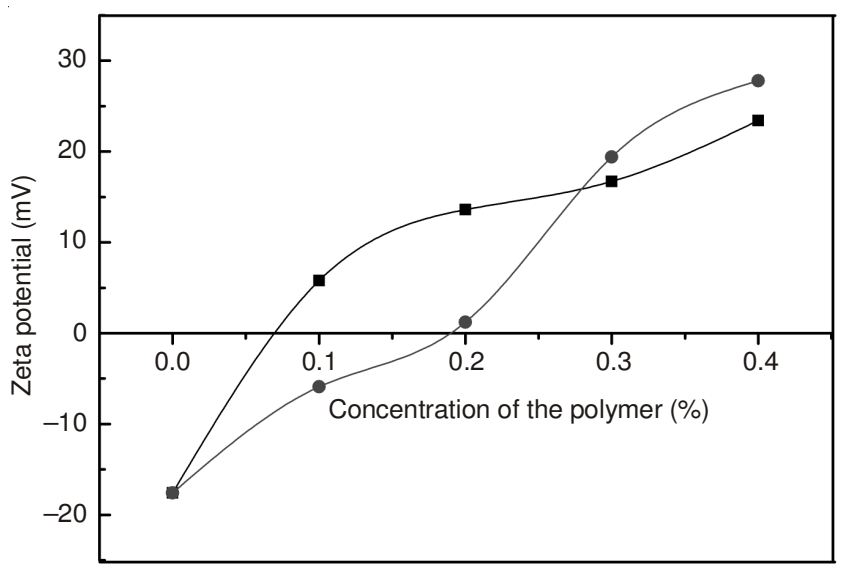

Fig. 9. Zeta potential of fine suspension upon the addition of CTS-ETA and CTS-ETA- $g$-PAM at pH 7 and $20^{\circ} \mathrm{C}$ (-m-: CTS-ETA, -•-: CTSETA- $g$-PAM)

Fig. 10 shows the surfaces of fibers modified with the polymer CTS-ETA-g-PAM. Evidently, the deposition of CTSETA- $g$-PAM complexes altered the surface morphology, which will affect the fiber-fiber friction as well as the fiber wall and bonding strengths. It was reported that the enhancement in the fiber wall strength and fiber-fiber friction increased the tear index of fiber networks ${ }^{42,46}$. Consequently, the fiber wall strength might increase by adsorbing polymers on the fibers or diffusing them into the fiber pores.

Antimicrobial activity of CTS-ETA-g-PAM: The antibacterial activities of the handsheets modified by CTS-ETA$g$-PAM against $S$. aureus and E. coli are shown in Table-3. Acrylic amide possessed some antibacterial properties. The antimicrobial effect were supposed to be improved as the PG of CTS-ETA-g-PAM increased. The antimicrobial activity against $S$. aureus was improved, however, no significant improvement of antimicrobial activity effect against $E$. coli was observed with higher PG of CTS-ETA-g-PAM. Different antimicrobial performance of CTS-ETA-g-PAM against $E$. coli and $S$. aureus might be attributed to their different cell walls. S. aureus is a typical Gram-positive bacterium, the cell wall of which is fully composed of peptide polyglycogen ${ }^{47}$. The antibacterial activity against $S$. aureus may be mainly due to a thin film formed by CTS-ETA- $g$-PAM, which can prevent cellular absorption of nutrients. The more degree of grafting of CTS-ETA- $g$-PAM with more side chains may be beneficial for forming the film on cell surfaces resulting in changes in permeability and the barrier function of cell wall. On the contrary, E. coli is a typical Gram-negative bacterium, the cell wall of which is made up of a thin layer of peptide polyglycogen and an outer lipopolysaccharide layer ${ }^{48}$. The outer LPS layer of $E$. coli cell wall is a potential barrier against foreign molecules with high molecular weight. No significant improvement of antimicrobial activity against $E$. coli could attribute to the more degree of grafting of CTS-ETA- $g$-PAM with more molecular weight and side chains inhibited CTS-ETA- $g$-PAM from permeating the cell wall. Therefore, the improvement of antimicrobial activities of acrylic amide would be attenuated.

\begin{tabular}{|c|c|c|}
\hline \multicolumn{3}{|c|}{$\begin{array}{c}\text { TABLE-3 } \\
\text { ANTIMICROBIAL ACTIVITY OF HANDSHEET MODIFIED BY } \\
\text { CTS-ETA- } g \text {-PAM WITH DIFFERENT PG. ALL THE } \\
\text { CONCENTRATIONS OF THE SAMPLES } \\
\text { USED FOR TESTS ARE } 0.25 \% \text {. }\end{array}$} \\
\hline \multirow{2}{*}{ PG of CTS-ETA- $g$-PAM (\%) } & \multicolumn{2}{|c|}{ Inhibition rate $(\%)$} \\
\hline & E. coli & S. aureus \\
\hline 0 & 71.4 & 76.2 \\
\hline 15.2 & 73.6 & 83.3 \\
\hline 20.3 & 74.7 & 90.4 \\
\hline 25.6 & 74.6 & 92.5 \\
\hline 31.3 & 75.4 & 98.3 \\
\hline
\end{tabular}
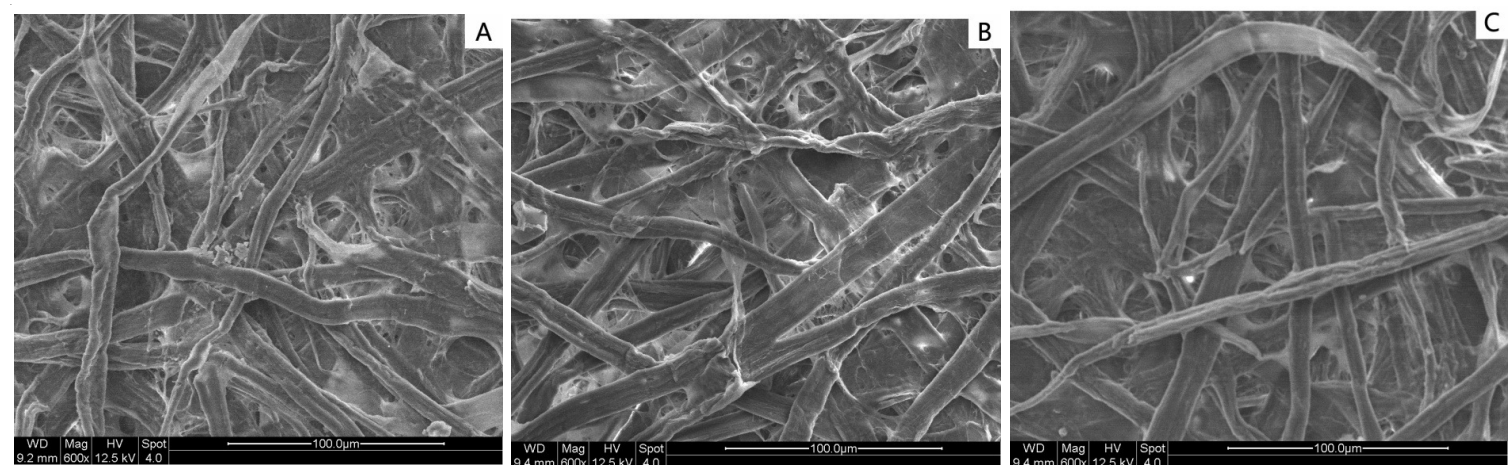

Fig.10. SEM photographs of the fiber surfaces (A: control, B: modified with CTS-ETA, C: modified with CTS-ETA- $g$-PAM) 
The antibacterial activities of the handsheets modified with CTS-ETA-g-PAM and CTS-ETA against $S$. aureus and E. coli were shown in Table-4. When the concentration of CTS-ETA$g$-PAM and CTS-ETA samples was lower than $0.1 \%$, both of them had no significant antibacterial effect against $S$. aureus and $E$. coli. However, the antibacterial effect on $S$. aureus and E. coli were improved rapidly, when the concentration of CTSETA- $g$-PAM and CTS-ETA reached $0.2 \%$. As the concentration of them rised to $0.35 \%$, the inhibition rate against $S$. aureus and E. coli reached 100 and $96.1 \%$, respectively. The results showed that the antibacterial activity of CTS-ETA-gPAM is relevant to its concentration. Thus, the concentration of CTS-ETA- $g$-PAM has vital influence on the antibacterial activities.

TABLE-4

ANTIMICROBIAL ACTIVITY OF HANDSHEETS MODIFIED BY CTS-ETA- $g$-PAM WITH DIFFERENT CONCENTRATIONS. THE PG OF THE POLYMER CTS-ETA- $g$-PAM WAS $31.3 \%$

\begin{tabular}{ccc}
\hline \multirow{2}{*}{ Concentrations of CTS-ETA-g-PAM $(\%)$} & \multicolumn{2}{c}{ Inhibition rate $(\%)$} \\
\cline { 2 - 3 } & E. coli & S. aureus \\
\hline 0 & 21.4 & 36.2 \\
0.10 & 26.6 & 42.3 \\
0.15 & 58.2 & 73.4 \\
0.20 & 70.6 & 84.5 \\
0.25 & 80.4 & 98.3 \\
0.30 & 88.9 & 100 \\
0.35 & 96.1 & 100 \\
\hline
\end{tabular}

\section{Conclusion}

CTS-ETA- $g$-PAM was prepared by grafting acrylamide onto main chains of the cationically modified chitosan. In the preparation of cationic chitosan CTS-ETA, the optimum reaction temperature, the molar ratio of ETA/CTS, the concentration of ETA and the reaction time were $80{ }^{\circ} \mathrm{C}, 3,30 \%$ and $8 \mathrm{~h}$, respectively. In the preparation of CTS-ETA- $g$-PAM by grafting method, the optimum initiator concentration, DS of CTS-ETA, reaction temperature, reaction time were $1.5 \mathrm{mmol} / \mathrm{L}, 0.369$, $35^{\circ} \mathrm{C}$ and $5 \mathrm{~h}$, respectively. The mechanical properties improved as the PG of CTS-ETA- $g$-PAM increased. It may be attributed to the fact that CTS-ETA- $g$-PAM with greater PG possesses more side chains, thus generating larger complexes among CTS-ETA- $g$-PAM, microparticle and the fiber fines. In addition, more CTS-ETA- $g$-PAM deposited on the surface of the fibers, altering the surface morphology of the fibers. This result can affect the fiber-fiber friction as well as the fiber wall and bonding strengths. The PG of CTS-ETA- $g$-PAM has no significant effect on antibacterial activities against $E$. coli, while the concentration of CTS-ETA- $g$-PAM has important influence on the antibacterial activities.

\section{ACKNOWLEDGEMENTS}

This research is financially supported by the National Nature Science Foundation of China (No.31270633), the Priority Academic Program Development of Jiangsu Higher Education Institutions and the Collegiate Program of Yiwu Industrial \& Commercial College (No. 2013029).

\section{REFERENCES}

1. L. Gärdlund, J. Forsström, B. Andreasson and L. Wågberg, Nordic Pulp \& Paper Res. J., 20, 36 (2005).

2. P. Fatehi, L. Qian, R. Kititerakun, T. Rirksomboon and H. Xiao, Tappi J., 29 (2009).

3. P. Fatehi, S. Ates, J.E. Ward, Y. Ni and H. Xiao, J. Tech. Assoc. Australian and New Zealand Pulp and Paper Ind., 62, 303 (2009).

4. J. Shen, Z. Song, X. Qian and F. Yang, Carbohydr. Polym., 81, 545 (2010).

5. A. Nada, A. Ibrahem, M. Yousef and S. El-Meadawy, Acta Polym., 34, 181 (1983).

6. H.J. Bixler and S. Peats, Paper Making using Hectorite and Cationic Starch, Google Patents, (1991).

7. P. Fatehi, A. Tutus and H. Xiao, Bioresour. Technol., 100, 749 (2009).

8. W. Gu, H. Li, H. Zhan, J. Ding and X. Zhang, J. Appl. Polym. Sci., 121, 2606 (2011).

9. M. Rinaudo, Prog. Polym. Sci., 31, 603 (2006).

10. M. Pereda, G. Amica and N.E. Marcovich, Carbohydr. Polym., 87, 1318 (2012).

11. R.A. Muzzarelli, J. Boudrant, D. Meyer, N. Manno, M. DeMarchis and M.G. Paoletti, Carbohydr. Polym., 87, 995 (2012).

12. P. Fatehi, R. Kititerakun, Y. Ni and H. Xiao, Carbohydr. Polym., 80, 208 (2010)

13. N.A. Yusof and K. Rashid, Asian J. Chem., 21, 1747 (2009).

14. H. Abbas, N.A. Abassi, A. Abassi, T. Yasin, M. Maqbool and T. Ahmad, Asian J. Chem., 20, 6217 (2008).

15. S.-H. Lim and S.M. Hudson, Carbohydr. Res., 339, 313 (2004).

16. H. Li, Y. Du, X. Wu and H. Zhan, Colloids Surf. A, 242, 1 (2004).

17. H. Chi, H. Li, W. Liu and H. Zhan, Colloids Surf. A, 297, 147 (2007).

18. S. Demarger-Andre and A. Domard, Carbohydr. Polym., 24, 177 (1994).

19. S. Demarger-Andre and A. Domard, Carbohydr. Polym., 22, 117 (1993).

20. M. Watanabe, T. Gondo and O. Kitao, Tappi J., 3, 15 (2004).

21. M. Sugimoto, M. Morimoto, H. Sashiwa, H. Saimoto and Y. Shigemasa, Carbohydr. Polym., 36, 49 (1998).

22. S. Lu, X. Song, D. Cao, Y. Chen and K. Yao, J. Appl. Polym. Sci., 91, 3497 (2004).

23. W. Sajomsang, P. Gonil and S. Tantayanon, Int. J. Biol. Macromol., 44, 419 (2009).

24. Z. Jia, D. shen and W. Xu, Carbohydr. Res., 333, 1 (2001).

25. V. Singh, A. Tiwari, D.N. Tripathi and R. Sanghi, Polymer (Guildf.), 47, 254 (2006).

26. R. Jayakumar, M. Prabaharan, R. Reis and J. Mano, Carbohydr. Polym., 62, 142 (2005).

27. K. El Tahlawy and S. Hudson, J. Appl. Polym. Sci., 89, 901 (2003).

28. Z. Zhu, T. Li, J. Lu, D. Wang and C. Yao, Int. J. Miner. Process., 91, 94 (2009).

29. P. Walker and T. Kelley, Bioresour. Technol., 90, 151 (2003).

30. Y. Lu, Y. Shang, X. Huang, A. Chen, Z. Yang, Y. Jiang, J. Cai, W. Gu, X. Qian, H. Yang and R. Cheng, Ind. Eng. Chem. Res., 50, 7141 (2011).

31. Y. Wei, F. Cheng and H. Zheng, Carbohydr. Polym., 74, 673 (2008).

32. X. Wan, Y. Li, X. Wang, S. Chen and X. Gu, Eur. Polym. J., 43, 3655 (2007).

33. T. Hongke, and Z. Penggang, Environ. Protect. Chem. Ind., 3, 019 (2006).

34. L. Raymond, F.G. Morin and R.H. Marchessault, Carbohydr. Res., 246, 331 (1993).

35. J. Luo, X. Wang, B. Xia and J. Wu, J. Macromol. Sci. Part A Pure Appl. Chem., 47, 952 (2010).

36. L. Sun, Y. Du, L. Fan, X. Chen and J. Yang, Polymer (Guildf.), 47, 1796 (2006).

37. A.J.M. Al-Karawi, Z.H.J. Al-Qaisi, H.I. Abdullah, A.M.A. Al-Mokaram and D.T.A. Al-Heetimi, Carbohydr. Polym., 83, 495 (2011).

38. X.-G. Chen and H.-J. Park, Carbohydr. Polym., 53, 355 (2003).

39. Z.- Cai, Z.- Song, S.- Shang and C.- Yang, Polym. Bull., 59, 655 (2007).

40. A. Hirai, H. Odani and A. Nakajima, Polym. Bull., 26, 87 (1991).

41. R. Pelton, Appita J., 57, 181 (2004).

42. P. Fatehi, and H. Xiao, Nordic Pulp \& Paper Res. J., 23, 285 (2008).

43. P. Fatehi and H. Xiao, Carbohydr. Polym., 79, 423 (2010).

44. J. Zhang and R. Pelton, Nordic Pulp \& Paper Res. J., 15, 440 (2000).

45. J. Zhang, R. Pelton, L. Wagberg and M. Rundlöf, J. Pulp Paper Sci., 27, 145 (2001).

46. C. Askling, L.A.R.S. Wagberg and C. Askling, J. Mater. Sci., 33, 1997 (1998).

47. X.-G. Chen, L. Zheng, Z. Wang, C.-Y. Lee and H.-J. Park, J. Agric. Food Chem., 50, 5915 (2002).

48. I. Helander, E.-L. Nurmiaho-Lassila, R. Ahvenainen, J. Rhoades and S. Roller, Int. J. Food Microbiol., 71, 235 (2001). 